\title{
EL MUNDO SEGÚN MARTA
}

THE WORLD ACCORDING TO MARTA

\section{RESUMEN}

Mediante el análisis de un caso clínico, este trabajo analiza algunos de los factores subyacentes que contribuyen al mantenimiento de los llamados trastornos de alimentación. Aparentemente, la anorexia es una lucha despiadada contra los esfuerzos de supervivencia del cuerpo; a pesar de lo cual, dota a este tipo de paciente de una fuerte identidad. Además les proporciona un rol especial para desempeñar en sus familias $y$, de alguna forma, les provee de un lugar propio en los grupos sociales a los que pertenecen; siendo éste un factor crucial, especialmente en la adolescencia. Este artículo contiene además un comentario sobre los factores esenciales que, en mi opinión, deberían ser tratados en la psicoterapia. Finalmente, se estudian algunos factores sociales que intervienen en el desarrollo de los trastornos de alimentación como la anorexia, la bulimia y el trastorno por atracón.

Palabras clave: Anorexia, psicoterapia, trastornos de alimentación, caso clínico.

\section{ABSTRACT}

Through the analysis of a case report, this work analyses some of the underlying factors contributing to the maintenance of the so-called eating disorders. Seemingly, anorexia is a ruthless fight of the patient $s$ with the survival efforts of the body; but, in spite of this, anorexia provides this kind of patients with a strong identity. It also provides them with a special role to perform in their families and, somehow, it supplies them with their own place in the social groups to which they belong; being this a crucial factor, especially when the patient is a teenager. This article contains as well a comment on the essential factors that, from my view, should be treated in psychotherapy. Finally, some social factors intervinig in the development of eating disorders such as anorexia, bulimia or binge-eating disorders are studied.

Key words: Anorexia, psychotherapy, eating disorders, case report. 
«Partiendo de la idea de que el self no nos es dado, tenemos que crearnos a nosotros mismos como una obra de arte»

Foucault

\section{UNA ARTISTA DEL HAMBRE}

Liz Eckerman, en un artículo en el que aplica algunas de las ideas de Foucault a los trastornos de la alimentación (1), expone que la persona que decide voluntariamente privarse de comida utiliza su cuerpo para representarse a sí misma. Se representa como una obra de arte tan provocadora que no puede ser ignorada. El mensaje expresado por este cuerpo desnutrido es «Léeme».

El día en que Marta cruzó la puerta de la consulta no pude evitar pensar en esta analogía entre la anorexia y el hecho de pintar un cuadro. A juzgar por su aspecto, ella parecía estar dedicándose en cuerpo y alma, nunca mejor dicho, a convertir su cuerpo en un fiel retrato del desolador aspecto de su mundo interno.

Marta parecía recién salida de un cuadro de Modigliani: palidez extrema, apariencia emaciada, cabello lacio. Su camisa dejaba entrever su piel seca, con aspecto acartonado, que hacía las veces de lienzo en este lúgubre cuadro que había comenzado a pintar hacía ya algún tiempo. La principal diferencia de este autorretrato con respecto a otros residía en que los trazos de la protagonista luchaban por desdibujarse bajo la palidez. En el fondo de este cuadro cuyos pliegues encarnaban las grietas que se habían estado fraguando en lo más hondo de su subjetividad, oculto bajo una inmensa capa del barniz de la tristeza, resonaba un llamamiento.

Aunque el esqueleto que hacía el papel de caballete en el cuadro de Marta parecía tener dificultades para seguir sosteniéndola durante mucho más tiempo, ella no venía por iniciativa propia. De hecho, sus comentarios revelaban cierta dosis de orgullo en relación con la obra de arte a la que se podría decir que estaba dedicando su vida.

Su madre, por el contrario, estaba alarmada por los resultados de las pruebas médicas. Éstas mostraban que Marta tenía hipotensión y bradicardia (pulso por debajo de los sesenta latidos por minuto), como si su corazón hubiera comenzado a latir en adagio porque únicamente pudiera soportar la vida que le iba llegando a dosis bajas. En los trastornos de alimentación suelen aparecer problemas en el aparato cardiovascular como la disminución del volumen cardíaco. Estos severos cambios estructurales se ven compensados por la hipotensión y la reducción del volumen sanguíneo.

Además, se produce una reducción de la sensación de dolor vinculada a la elevación en los niveles de endorfinas. Este hecho, induce un estado de analgesia del que luego les resulta complicado prescindir. Marya Hornbacher, una paciente que plasmó su experiencia con la anorexia en «Días perdidos» (2), comenta «Estar hambrienta 
tiene el mismo efecto que una droga, una se siente fuera de su cuerpo y entonces se puede sobrellevar el dolor». Al parecer, la deprivación de alimentos adormece las emociones, especialmente la ansiedad, y se activan en el organismo sistemas de emergencia para atajar el sufrimiento tan efectivos que luego al sujeto le resulta difícil renunciar a ellos.

Algunas anoréxicas se quejan del frío o del insomnio. Marta, sin embargo, decía sentirse cómoda en el invierno perpetuo en el que se había instalado y aprovechaba la lucidez atroz del insomnio, como decía Borges, para estudiar por la noche a ritmo frenético.

Con todo, pese a su aparente felicidad, los repetidos desmayos que padecía revelaban su necesidad de perder el mundo de vista de vez en cuando. Además, había llevado a cabo un par de intentos autolíticos hacía unos años, lo que sugería su incesante búsqueda del punto del fuga que la sacara de ese marco que la protegía y, al mismo tiempo, la tenía secuestrada como rehén.

Antes de adentrarnos en el mundo de Marta y alejarnos demasiado del mundo objetivo en el que acostumbramos a sentirnos más cómodos, vamos a examinar los datos de los que disponemos. Se trata de una paciente de 19 años en torno a 50 kilos de peso. Refería una frecuencia de atracones seguidos de vómitos de 3 a 4 veces por semana. Sus problemas de alimentación comenzaron a los 15 con restricción alimentaria y ejercicio físico excesivo. A los 17 años fue hospitalizada en un hospital de Valencia por presentar un Indice de Masa Corporal (IMC) de 17.26, había perdido algo más del $25 \%$ de su peso. En aquella época comenzaron los episodios bulímicos y el uso de laxantes y diuréticos.

\section{EL MUNDO SEGÚN MARTA}

Desde la perspectiva cognitiva-constructivista de Guidano (3) se afirma que los mundos que vamos creando para dotar de sentido a nuestra realidad externa e interna son lugares en los que luego estamos condenados a habitar. Nuestra identidad se aloja en cada uno de esos mundos que construimos. Como luego veremos, los problemas de identidad son un aspecto esencial en este tipo de trastorno.

El mundo donde habita Marta se sostiene solamente a fuerza de ayuno. Dice que tuvo que exiliarse allí porque se hartó de vivir agonizando bajo el peso de la imagen que los demás, especialmente sus familiares, tenían de ella. Los insultos que sus compañeros la dedicaban debido a su sobrepeso, el aumento de la exigencia del nivel académico y la primera vez que la mirada de un chico se posó sobre su cuerpo destruyeron el silencio corporal del que había disfrutado hasta entonces. La mirada del otro hace que el cuerpo no pueda ser pasado por alto dice Merleau-Ponty (4). El contacto con otro cuerpo te recuerda que tú también tienes uno, un hecho que la anoréxica intenta olvidar por todos los medios. 
Ella comenzó a los 15 restringiendo los alimentos que ingería. Comía lo justo para fingir que aún seguía viva. Después empezó a perseguir la soñada ingravidez a bordo de su bicicleta estática y se inició en el uso de los laxantes y diuréticos. Cada vez que tiraba de la cadena la imagen ideal que los otros tenían de ella se alejaba cada vez un poco más.

Decidió quedarse en ese mundo que la anorexia le brindaba porque le proporcionaba una identidad más aceptable para ella. Marta dice que la anorexia fue la primera decisión seria que tomó con respecto a su vida. Hornbacher (2) dice «La anorexia fue mi gran idea, mi esfuerzo por hallar la independencia, una identidad, la libertad». Esa nueva identidad estaba sostenida principalmente en una cifra: la que marca la báscula. La anorexia dota a la paciente de una identidad tan frágil que, como luego veremos, corre el riesgo de tambalearse fácilmente.

Ese mundo era al principio insoportablemente vívido. La deprivación adormece las emociones, pero al mismo tiempo agudiza los sentidos de la visión y la audición. Las anoréxicas son, en los inicios del trastorno, hipersensibles al sonido, a la luz. Esa agudeza sensitiva las hace sentir que viven algo especial. Se produce también la desconexión de sus propias emociones y sensaciones (especialmente las de hambre y saciedad), de manera que gradualmente se van rompiendo los puentes que las unen consigo mismas.

Muchas pacientes dicen que el ayuno es adictivo debido a los efectos reforzantes inmediatos: aumento de vitalidad, aumento de energía, sentimiento de euforia por no tener necesidades... «Yo soy la heroína de mi misma» dice Hornbacher (2). Como sucede en otras adicciones, con el tiempo la dosis que necesitas para alcanzar ese efecto inicial es cada vez mayor. Otros reforzadores que contribuyen al mantenimiento del trastorno son la admiración de familiares y amigos y el consiguiente aumento de autoestima tras la pérdida de peso.

Por otra parte, el ayuno genera pensamientos y comportamientos obsesivos. Son frecuentes los rituales a la hora de comer: fragmentar la comida en partículas infinitesimales, comer los alimentos en un orden determinado... Los rituales con la comida y con la balanza proporcionan cierta predictibilidad en momentos caóticos de su vida. Por lo general, tratan de seguir un montón de reglas rígidas que pueden resumirse en una sola: «Todo lo que entra, debe salir».

Marta siguió siendo etérea, casi evanescente, durante algún tiempo; pero la piel que la cubría, ese velo que en su empeño de ser translúcida apenas la ocultaba ya, se fue convirtiendo poco a poco en una camisa de fuerza que coartaba su libertad. En ese momento accedió a recibir tratamiento en Valencia cuando tenía 17 años.

Es curioso el papel que juega la libertad en este trastorno. Hilde Bruch (5) titula uno de sus libros «La jaula dorada» en honor de una paciente que decía que la anorexia era una jaula dorada que ella misma había decidido construir para deslumbrar a los demás. Es como si estas pacientes tomasen la decisión de esclavizarse para conquistar por fin una libertad de la que jamás habían disfrutado. 


\section{VIVIR EN PRIMERA PERSONA}

Se ha sugerido que la anorexia representa un intento de hallar una identidad. En las familias de estas pacientes, la falta de límites entre los miembros de la familia y la falta de intimidad son tales que no es exagerado decir que algunas pacientes tienen miedo a no tener un cuerpo propio.

Hilde Bruch (5) ha descrito lo que denomina «confusión de pronombres» que caracteriza el estilo de comunicación de estas familias, ya que cuando hablan es difícil saber en nombre de quién están hablando. Cada miembro parece saber lo que piensan y sienten los demás y, a la vez, descalifica lo que el otro acaba de decir con sus interpretaciones.

Para desarrollar un sentido de identidad adecuado es necesario que los que nos rodean refuercen nuestros deseos, necesidades y pensamientos. Desde el conductismo se defiende que la comunidad verbal, especialmente nuestros padres, conforma a través del lenguaje nuestra experiencia subjetiva. El lenguaje constituye la conciencia que tenemos de nuestro mundo externo e interno. Si, tal y como decía Marta, muchos de los deseos que regían su vida, como la carrera de ingeniería que estudiaba, le habían sido impuestos, gran parte de su subjetividad le era ajena.

«Marta disfruta estudiando», dice su madre o «No la gusta beber o fumar como a otros chicos de su clase». Podría decirse que hasta que la anorexia apareció en escena, había vivido refugiada en la ambigüedad indolora de la tercera persona, interpretando el papel de esa «ella» que la habían construido a su medida sin tener que asumir las riendas de una vida en primera persona. Esa «ella»era un falso self o pantalla que la protegía de darse de bruces con una realidad casi siempre excesiva y de la despiadada luz cenital que cae de lleno sobre el yo protagonista. Desde esa posición pudo vivir de forma segura durante algún tiempo, pero cuando se fue haciendo mayor empezó a dudar hasta de si los deseos que pedía de pequeña ante las velas habían sido realmente los suyos.

«¿Quién soy yo realmente?» Es una pregunta que resuena en la cabeza de la mayor parte de adolescentes. En el caso de Marta podría haber contestado como un personaje de Pirandello: «No tengo identidad, sólo hay el reflejo de lo que los otros esperan que yo sea, yo soy como tú quieras que sea».

El proceso de individuación implica inevitablemente, según Erich Fromm (6), el aumento de la soledad. Ortega o Kierkegaard hablaron de esta soledad radical del individuo en su desértica travesía por el periplo cotidiano. La verdadera desgracia radica para Kierkegaard (7) en basar el contenido de la vida fuera de uno mismo, en un ideal externo, convirtiéndose en extraño para su propia alma. El desdichado está siempre ausente de sí mismo, nunca enteramente presente, en la periferia de su ser.

Fromm (6) habla de la ilusión de individualidad en una sociedad que destaca por la creciente estandarización de los individuos. Al tratar de no ser diferentes, logramos acallar aquellas dudas acerca de nuestra identidad, obteniendo así cierto grado 
de seguridad. En la adolescencia, se demanda normalmente mayor libertad. Pero a menudo se olvida que la libertad es el derecho a construir nuestra propia diferencia; consiste en desafiar a quienes nos sustituyen a la hora de decidir nuestra identidad. Ser un individuo por derecho propio conlleva soledad, ahí reside, según Fromm, nuestro miedo a la libertad; implica llevar sobre los hombros la carga de uno mismo, siendo éste un peso excesivo para alguien que no está acostumbrado a ejercerla. Al fin y al cabo, apunta Dostoievski (9) la libertad es ese don con el que tenemos la desgracia de nacer.

En cuanto a Marta, no había sido más que el peón del peón en el tablero de su vida, y de repente la vida le puso en la tesitura de ocupar el sillón de la reina. Desgraciadamente, el único reino donde podía gobernar era su cuerpo y por eso acabó imponiendo sobre él una tiranía.

\section{LA SEGURIDAD DE LOS OBJETOS}

La crónica de su niñez es el relato de una existencia invadida por la materialidad. «No puedo entenderlo, siempre ha tenido de todo». Este tipo de frases son habituales en los familiares de estos pacientes.

La madre de Marta se quejaba de que ésta había convertido su habitación en una especie de templo privado. No dejaba que nadie entrara ni siquiera a limpiarla. Marta decía sentirse a salvo allí, refugiada en la seguridad de los objetos que siempre la habían rodeado. También era el lugar donde decía sentirse más sola.

En aquella especie de santuario a la soledad se representaba una y otra vez la obra de teatro de su vida. Una obra en la que ella había sido simplemente un extra que anhelaba su propia aparición estelar y los objetos eran los auténticos protagonistas.

Las muñecas estaban protegidas por una cortina de polvo que ella no permitía que nadie rasgase. El polvo es una sustancia en la que se conjugan de forma magistral lo presente y lo ausente, pero ¿en conmemoración de quién era conservado ese mausoleo? Antonin Artaud decía que se sobreentiende que la vida es siempre la muerte de alguien. La nueva vida que se abría ante ella con la adolescencia, implicaba inevitablemente la muerte de aquella niña en cuyo cuerpo se había sentido a salvo.

Todo lo que había en aquella habitación la rendía homenaje. Todo tenía un insoportable sabor a ella misma. Allí donde reposamos nuestra mirada depositamos algo nuestro. Sea cual sea el objeto que cautive nuestros ojos, se lleva consigo una parte importante de nosotros mismos. Desprenderse de aquellas cosas supondría echar una palada de tierra definitiva sobre la niña que fue.

Como allí pasaba horas estudiando y no tuvo hermanos, sus padres se encargaron de rodearla de cosas, de forma que ella creció envuelta en la pasividad de la materia. Los objetos existían a pesar de si mismos, ella tenía que esforzarse en existir. Sólo podía realizar su deseo de ser fuera de sus padres, quienes, en cierto modo, habían 
robado su vida al haberla encargado la difícil tarea de llevar a la práctica su proyecto vital. El suyo fue un nacimiento «teleológico», su esencia: obturar un agujero en la cabeza de sus padres, el dejado por el que fue el hermano mayor de Marta.

\section{EXILIADOS DE LA SUBJETIVIDAD}

Muchas veces, los familiares de estas pacientes hablan de ellas como del objeto opaco que ha cubierto de sombra su vida. La anoréxica es tratada a menudo como un objeto, sin necesidades o deseos por derecho propio hasta que acaba convirtiéndose en uno de ellos. Se siente reducida a carne ante los ojos de los demás. No es de extrañar que, tal y como expone Graciela Strada (9), la anoréxica, toda ella, su propio cuerpo se haga puro objeto, quedando exiliada de su subjetividad.

En los trastornos de alimentación el cuerpo es tratado como un objeto que puede ser rellenado y vaciado. Estas pacientes ansían conformarse a lo establecido y, a la vez, buscan la transgresión de los límites que delimitan la llamada normalidad.

Foucault (10) muestra que las relaciones de poder pueden penetrar materialmente en el espesor mismo de la carne. En «Vigilar y castigar» reflexiona sobre la forma en que la sociedad controla a los individuos adiestrando sus dóciles cuerpos. Ahora, somos nosotros mismos los encargados de vigilarnos y juzgar si nos mantenemos dentro de la normalidad o si, por el contrario, nos merecemos un castigo. El individuo se ha erigido en su propio carcelero. Por irónico que parezca, muchas mujeres deben seguir vigilando y siendo conscientes de su cuerpo para no ser martirizadas por su conciencia corporal. En la anorexia, el cuarto de baño se convierte a menudo en un patíbulo donde la anoréxica se ahorca, en sentido figurado, metiéndose los dedos en la garganta cada vez que juzga que no está a la altura, o mejor dicho a la anchura, de los estándares sociales.

Además, es una lucha del individuo consigo mismo. Mirado desde el existencialismo, el hombre está solo y sólo él inventa la ley a la que se somete, siendo para sí mismo una víctima y un verdugo.

La constante estética contemporánea predominante apunta al deseo contradictorio de «sentirse como una cosa». Se tiende a borrar la distinción entre lo animado y lo inanimado. Así, el cuerpo se convierte en un fetiche con la materialidad propia de un objeto precioso.

\section{LA IMAGEN COMO FETICHE}

Aunque el tiempo la alejaba de la época en que jugaba con las muñecas, el moho dejado por su paso contribuía a ocultar los recuerdos de los insultos que sus compañeros de clase la dirigían cuando comenzó a adquirir las formas propias de una mujer. Esos insultos, pensaba ella, quedarían sepultados en el fondo de su memoria, sumergidos para siempre bajo el peso de su nueva imagen. 
En estos trastornos, la imagen del cuerpo delgado se convierte en un fetiche. Autores como Kestemberg, de la corriente psicodinámica, han subrayado este aspecto.

En su empeño por borrar la materialidad de esos malos recuerdos, Marta contemplaba su nuevo aspecto repetido hasta la extenuación en escaparates y ventanas de coches, con la esperanza de que su nueva imagen tapase su imagen anterior. La vida del hombre es una serie entrecortada de instantes. Marta, a fuerza de fotografiarse, pretendía anular ciertos momentos coagulados en su retina. Ella se hacía fotos al igual que otras personas llevan un diario en el que recogen los restos de cada día antes de morir, pero lo que escribimos hoy, aunque escribamos sobre la página de ayer, no hace que la tinta que está debajo desaparezca. De hecho, algunas palabras del fondo a veces son dolorosamente legibles.

Toda fotografía, dice Barthes (11), es siempre una catástrofe. Lo que la fotografía reproduce hasta el infinito ha tenido lugar únicamente una vez. Por así decirlo, repite mecánicamente lo que nunca más podrá repetirse existencialmente. Incluso los momentos perfectos tienen un defecto: el de ser vividos solo una vez. Nietzsche ya anunció la imposibilidad de la felicidad del hombre mientras el tiempo siga teniendo una estructura lineal. La catástrofe de Marta era la de no poder volver a tener jamás 9 o 10 años.

Por otra parte, una fotografía es un certificado de presencia, autentifica la existencia del ser. La vida privada, continúa el filósofo francés, no es más que esa zona del espacio, del tiempo, en la que no soy ni una imagen ni un objeto. Se refiere a la zona en la que se es sujeto. Tal vez el cobijo que encuentra la anoréxica en la imagen corresponda a esa carencia de privacidad, de mundo interno propio, dificultades éstas propias de un sujeto que todavía no ha empezado realmente a ser. Para Alain Ehrenberg (12) la adicción es la nostalgia de un sujeto perdido. Siguiendo con esta analogía, se podría decir que la anorexia refleja la lucha de un sujeto por empezar por fin a ser.

Algunos sociólogos como Baudrillard (13) comentan los peligros de una identidad basada exclusivamente en una imagen: «El hombre, a base de representar su imagen, ha creado un territorio donde la carnalidad, la humanidad ha desaparecido».

\section{EL PARAISO PERDIDO}

«Ellos intentaron construirlo a su manera, pero aquella ciudad no era más que una parodia del cielo. Habian perdido el cielo y querían recuperarlo. No querían crear una parodia, sólo querían escapar del sufrimiento, no construir su sede. Su ciudad materialmente bella, pero como les faltaba el espiritu del cielo, el resultado era un tanto grotesco, absurdo y trágico» (John Milton, El paraíso perdido) 
Esta descripción de Milton (14) acerca de la creación del infierno puede ser una buena metáfora de lo que sucede en los trastornos de alimentación. Las pacientes quieren evitar la ansiedad, el sufrimiento, el vacío pero acaban construyendo su sede, convirtiéndose ellas mismas en un monumento conmemorativo a la muerte. En un principio su obra puede ser materialmente bella, como dice Milton, pero poco a poco se convierte en un lugar inhabitable, un lugar donde solo es posible una vida casi a título póstumo.

Cuando la anorexia se desarrolla en la fase de crecimiento puede producirse una detención de éste. Esto puede leerse como un intento desesperado de seguir siendo niñas. «No quería crecer», suelen reconocer retrospectivamente. Marta era también una niña que se resistía a morir de forma natural. Mediante la anorexia consiguió que su organismo fuese como un reloj estropeado que siempre marca 13, pero éste fue un éxito a medias. Consiguió acallar por el momento aquel despertador que había comenzado a sonar de una forma tan ruidosa, se las ingenió para arrancar las agujas de su reloj biológico, pero el tictac continuaba. Marta dejó de ser esclava de las agujas del reloj, pero comenzó a ser sierva de la aguja de la báscula. Sobre ella, sólo hay una cosa que la anoréxica sopese a la ligera: su propia vida. Como diría Nietzsche, la anoréxica termina por poner su existencia misma en la balanza y la encuentra demasiado liviana. Eso debió de pensar ella las dos veces que, como ya he comentado, intentó suicidarse.

\section{EN BUSCA DEL CUERPO PERDIDO}

La adolescencia es una crisis temporo-espacial sin precedentes. No querer crecer es una batalla contra el cuerpo y contra el tiempo. Implica evadirse de la estructura edípica del tiempo en la que, tal y como expone Gianni Vattimo (15), cada instante es un hijo que devora a su padre (el momento que le precede) y está destinado a su vez a ser devorado. Volver a recuperar ese cuerpo perdido supone sortear la cronología vigente. El pasado es un lugar imposible. Es inútil tratar de conquistar el tiempo. El único logro al que puede aspirar el ser humano es conseguir olvidarlo aunque sea un instante (16).

La anorexia suele aparecer cuando las primeras formas del cuerpo femenino hacen acto de aparición. La amenorrea marca un tiempo muerto. Durante cierto tiempo, convierten su vientre en una tierra baldía. «No es miedo al sexo, sino vergüenza a que te vean como ser sexual» decía una paciente. La sexualidad femenina sigue siendo muy ambigua en nuestra cultura. Muchas mujeres se sienten amenazadas por la sexualidad naciente de sus hijas, son incapaces de validar los cambios que están aconteciendo en sus cuerpos. No es de extrañar que algunas adolescentes no sepan encajar dichos cambios e incluso se sientan culpables. 


\section{MITOS FAMILIARES}

Las familias de pacientes con anorexia se caracterizan por la negación del conflicto. Frecuentemente afirman que su único problema es la enfermedad de su hija, que si no fuera por eso seguirían siendo una familia perfecta. Lo cierto es que no es extraño que cuando la paciente mejora aparezcan conflictos familiares que habían permanecido encubiertos. Los modelos sistémicos consideran que la anorexia contribuye a la homeostasis familiar desempeñando una función protectora de la expresión de otros conflictos.

No suelen ser familias que discutan de forma violenta, pero el silencio puede ser también un arma de destrucción masiva. Este afán en acallar los problemas hace posible que se produzca en muchas anoréxicas una metamorfosis del calibre de la narrada por Kafka sin que nadie en casa ponga el grito en el cielo. Así Marta adelgazó 10 kilos en poco tiempo sin que nadie en su familia pareciera darse cuenta.

Dentro del modelo sistémico, Watzlawick y cols. (17) estudia los mecanismos que sostienen el equilibrio de las familias por muy precario que éste sea. Así, por ejemplo, analiza los mecanismos homeostáticos que sostienen la «estabilidad» de la pareja protagonista de la obra de teatro «Quien teme a Virginia Woolf». Esta pareja se mantenía unida únicamente por un macabro juego de humillaciones recíprocas pero, sobre todo, por el mito de un hijo ficticio que al final de la obra muere. Los padres de Marta no se insultaban, simplemente se ignoraban el uno al otro como si sus vidas fuesen líneas paralelas condenadas a no cruzarse nunca. Lo que les unía pero les separaba a la vez era un niño que nunca llegó a existir del todo. Hubiera sido el hermano mayor de Marta, nació de forma prematura y su existencia fue forzosamente confiada a una máquina. Tras algún tiempo, falleció en la incubadora.

La madre de Marta dejó de trabajar cuando se quedó embarazada de ella, siempre pensó que si se hubiera cuidado más en su primer embarazo habría llegado a buen término. Con Marta siempre fue muy sobreprotectora y, por tanto, soterradamente desvalorizadora.

Dice que su marido estaba muy ilusionado con aquel bebé, se pasaba las horas contemplando cómo era alimentado de forma artificial. Esa incubadora, explica su mujer, es el lugar donde sus palabras acabaron; ya que desde entonces se volvió más callado. De hecho, muchos años después seguía sumido en aquel minuto de silencio.

A la hora de comer el silencio en casa de Marta es ensordecedor porque es la hora en que los tres silencios convergen. La televisión es con mucho la que más habla en esa casa. Su padre trabaja en un banco y también habla mucho, aunque con el móvil. Su madre, por su parte, practica el más seguro de los mutismos, el que no consiste en callar sino en hablar (7). «Le encanta hablar en mi nombre», dice Marta. Esta afirmación concuerda con la noción de «confusión de pronombres» que utiliza Hilde Bruch para describir el estilo de comunicación de estas familias. 
Rara vez discuten entre ellos, pero «desde que Marta está así» como dice su madre, su padre la reprocha que se parece mucho a su madre y su madre, por su parte, la riñe porque es igualita que su padre. En esos momentos, la expresión «las palabras son pistolas cargadas» es más cierta que nunca.

Marta siente por su madre una inmensa compasión acompañada de un sutil desprecio. Tiene sobrepeso y ha hecho dieta desde siempre, pero ahora que ha entrado en el cuarto menguante de su vida cada vez le importa menos. Selvini-Palazzoli (18) expone que muchas anoréxicas tratan de arrancar de sí todo rasgo de semejanza con su madre, siendo ésta un modelo inaceptable para la hija por ser sacrificadas y «encajadoras de humillaciones». Además, en casa de Marta había cierta confusión de roles: su madre era a su vez una niña dominada por su abuela que también vivía allí.

Durante la evaluación se puso de manifiesto que Marta mostraba características parecidas a su madre aunque había una fuerte discrepancia entre esas características con lo que ella desearía ser. Por el contrario, su padre era descrito por ella como más parecido a su yo ideal. Marta adoptaba su frialdad y trataba de conseguir cosas que él apreciaba, especialmente logros académicos, pero nunca parecía bastante. Veía a su padre como alguien inalcanzable ante el cual ella se sentía pequeña, prácticamente inapreciable. Daba la impresión de que Marta creía que nunca podría reemplazar a aquel bebé cuyo duelo no había sido bien elaborado.

Su padre tendía a aplastar con sus razonamientos el brote de cualquier emoción. Según el conductismo, se siente precisamente de la manera en que se nos enseña a sentir. Los sentimientos y su expresión son moldeados por la comunidad verbal que nos rodea, especialmente los padres. Si la expresión de sentimientos rara vez es reforzada, como en este caso, no es exagerado decir que la subjetividad resultante estará en gran medida mutilada.

\section{EL VIRAJE}

«Rebeca se levantó a medianoche y comió puñados de tierra del jardín, con una avidez suicida, llorando de dolor y furia, masticando lombrices tiernas y astillándose las muelas con huesos de caracoles. Vomitó hasta el amanecer». «Practicaba este hábito de comer la tierra húmeda y la cal que arrancaba de las paredes con las uñas a escondidas y con conciencia de culpa» (García Márquez, «Cien años de soledad»)

Una esclusa se levanta el primer día que vomitan. Casi todas las anoréxicas lo recuerdan. Todas coinciden en señalar que el vómito las absuelve de la culpa que sienten tras el atracón 0 , simplemente, tras haber comido más de la cuenta según sus rígidos criterios. 
El comportamiento de control sobre la comida funciona como una defensa frente a sentimientos de angustia y depresión. Cuando los sentimientos depresivos son más intensos, la defensa cede y la paciente se abandona al atracón. Al principio del trastorno el cuadro es más organizado, priman los síntomas obsesivos y el control rígido, luego se vuelve más desorganizado.

Se ha dicho que el impulso bulímico es más realista porque, pese a su nihilismo espeluznante, comprende que el cuerpo es ineludible. La anorexia funciona bajo la ilusión de que se puede escapar de la carne. Se rige por una ecuación digna de las matemáticas del caos: la valía de una persona es directamente proporcional a la gradual desaparición de la misma. La anoréxica se empeña en abolir su cuerpo, en negarse físicamente hasta el extremo y muchas de ellas casi logran ser bidimensionales. La identidad gravita en torno a la cifra marcada por la báscula, ésta se convierte en testigo del vía crucis emprendido por la anoréxica hacia la nada. Irónicamente, su autoestima aumenta cuanto más logra acercarse al espacio vacío, a esa especie de agujero negro donde el tiempo y el espacio ya no significan nada. Se trata de hacerse invisible de una forma bien visible. Kafka en «El artista del hambre» relata las experiencias de un artista que hace un espectáculo del hecho de ayunar; finalmente éste confiesa que el principal espectador del show fue siempre él mismo.

El silencio de la anorexia generado por su obstinación en no abrir la boca, da paso al retumbar de la mente de la bulimia. En esta fase las campanas empiezan a doblar ya que la pulsión de muerte se manifiesta ahora de una forma más ruidosa. Durante un atracón muchas dicen querer comer hasta que el estómago reviente. Lo temen y lo buscan por igual. En la bulimia, se pone de manifiesto de una forma más abierta el desprecio que sienten hacia ellas mismas: por mucho que adelgacen, bajo la piel ajada donde se atrincheran, siguen estando ellas.

Durante el atracón algunas pacientes dicen sentirse separadas de su cuerpo, y mediante el vómito vuelven a reunirse con él. En el marco de la psicología cognitivo-conductual, Favazza (19), elabora la hipótesis del escape para explicar esta despersonalización que refieren sentir durante el atracón. Según él, el atracón es un medio de escapar de una autoconciencia demasiado aversiva. En esos momentos, se produce un estrechamiento cognitivo. El foco de atención se reduce a las sensaciones corporales inmediatas.

Esta maniobra puede ser eficaz a corto plazo pero como señala Albert Camus (20) no podemos hacer nada para escapar del extraño que viene a nuestro encuentro en el espejo. Al parecer, tampoco podemos escapar, al menos por mucho tiempo, de lo reflejado en el «espejo interno» que llamamos conciencia. El conocimiento reflejo que es la conciencia de sí, parece ser esencial para comunicarse con los demás, dice Nietzsche en «La gaya ciencia» (21). Skinner desde el conductismo, llega a una conclusión similar. Este espejo que no tenemos otro remedio que portar es el principal acceso que tenemos a nosotros mismos pero, en gran medida, reduce al ser humano a la cruel posición de espectador. 
En otro orden de cosas, se han descrito también las diferencias en la forma de experimentar las relaciones sexuales en función de la fase del trastorno en la que se encuentren. En la anorexia el cerebro deserta, el sexo no se experimenta, se ve a cierta distancia, el cerebro traduce la experiencia física en ejercicio intelectual. En la bulimia algunas pacientes dicen servirse del sexo para llenar un vacío. La otra persona es consumida al igual que se devoran los alimentos durante el atracón.

Desde el psicoanálisis, Recalcati (22) explica el viraje hacia la bulimia como el resultado de la desestabilización de esa identidad ficticiamente mantenida del ideal anoréxico. La anorexia, desde esta lectura, configura una identificación nueva. Esta identidad se sostiene básicamente en la ausencia (los huecos entre las costillas, la desaparición de los pechos, la carencia de curvas...) y en una cifra, la que marca la báscula. Es una incongruencia ya que lo que hace existir a la anoréxica es precisamente lo que ya no es. Dada la fragilidad de esa identidad basada en un número y en la ausencia, el no-ser o la nada, cuando el afecto depresivo es mayor, se tambalea.

\section{CUANDO LA CARNE ROMPE SU SILENCIO}

Los cuerpos que han sido convertidos en fetiche en nuestra cultura, son cuerpos cerrados, y no me refiero al cuerpo cercado del que ningún ser humano podrá salir jamás con vida, sino a los cuerpos sin porosidades, sin carnalidad, sin posibilidad de intercambio. Se trata en definitiva de cuerpos descorporeizados y, por tanto, deshumanizados, casi inorgánicos. La piel, hoy día, es más un signo de prestigio y distinción que el órgano por excelencia de la sensibilidad. Para Baudrillaard (13) el cuerpo fue tiempo atrás la metáfora del alma, después la metáfora del sexo, hoy ya no es la metáfora de nada.

La adolescencia es el período de duda metódica por excelencia. En ese período, uno se enfrenta a la tarea de saber si existe como individuo independiente. Para resolver este enigma de magnitud cartesiana, Marta volvió su mirada hacia dentro y no encontró a nadie a quien ella pudiera reconocer como «yo».

Marta cometió la misma osadía que Descartes, pensó que era posible ser pura racionalidad. Descartes afirmó «Puedo fingir que no tengo cuerpo y que, sin embargo no por ello soy nada». Hornbacher (2) afirmaciones parecidas: «Quería que desapareciera mi cuerpo, ser alma pura, cerebro andante». Marta creía que no necesitaba para nada el cuerpo, sólo que ella trató de llevarlo a la práctica literalmente. Empezó a poner en duda la validez de sus propias sensaciones, dejó de reconocerlas como propias. Durante un tiempo consiguió mantener sus necesidades corporales a raya, pero llegó un momento en que el cuerpo reclamó el lugar que le correspondía y la mente acabó anegada por lo material.

Como un personaje de Blanchot (23) nacemos encadenados a un compañero casi mudo: el cuerpo. Como él, cuando rompemos las cadenas que nos sujetan al cuerpo nos perdemos. Bajo esos intentos de romper las cadenas subyace un intento de evadirse 
de la carnalidad que está sujeta al envejecimiento y a la mortalidad. Hoy día, hacemos del cuerpo un trozo de materia esclavizado (le privamos de comida, le sometemos a trabajos forzosos en un gimnasio...) hasta que un día el cuerpo toma las riendas del pensamiento e invade por completo el campo de conciencia. Este compañero de cadena que tratamos en vano de obviar, está siendo maltratado en una sociedad que ha declarado el divorcio irreconciliable entre lo físico y lo espiritual.

La dicotomía cartesiana no ha sido superada aún. Así, las pacientes para explicar los atracones dicen cosas como: «Tú quieres morir, tu cuerpo quiere vivir. El cuerpo empieza a comer por iniciativa propia para salvarse»o «mi verdadero yo es sin carne, mi verdadero yo es el que tengo en la cabeza». Esta es la premisa que parecen seguir algunas anoréxicas. Inician una búsqueda de su «verdadero yo» que creen oculto bajo los pliegues de su carne, por eso van borrando su cuerpo capa a capa, lo corroen por dentro con vómitos y laxantes con la esperanza de que cuando no quede un gramo de carne podrán por fin ser ellas.

El dualismo aparece también en la forma de hablar de los profesionales. Así, Selvini-Palazzoli, afirma que «en la anorexia el cuerpo ocupa la mente: es el interlocutor de la mente como amo, fetiche o enemigo». Se ha descrito la anorexia como una aventura sadomasoquista del individuo con su propia imagen. El dualismo hace que sea posible experimentar a la vez el placer de azotar un cuerpo esposado y el placer de ser ese cuerpo y de saber que merece cada azote que recibe. Está tan arraigado en el lenguaje que empleamos que, inevitablemente, modula la experiencia que tenemos de nosotros mismos. Es difícil no caer en él cuando la trama misma del lenguaje lo perpetúa conforme razonamos y hablamos.

Herbert Marcuse (24) habla de la ideología de la muerte. Partiendo de una escisión brutal entre cuerpo y espíritu, se declaró digno o, al menos indiferente, sacrificar al primero en aras del segundo. Esta ideología justifica un absoluto desprecio de la carne, tanto propia como ajena.

El sujeto cartesiano exilió el cuerpo, pero éste ha acabado reclamando su lugar. En el campo de la psiquiatría atravesamos una era que podría llamarse de la «somatización del alma» debido al predominio de la tendencia biologicista que ha llevado a la medicalización de la locura. Fuera de ese campo, el cuerpo es también protagonista hasta el extremo de que parece haber sustituido al alma como objeto de salvación. Hoy, el pecado es envejecer 0 «dejarse».

La salud se manifiesta por el silencio corporal dice Merleau-Ponty (4). Vivir el cuerpo, continúa el filósofo francés, es aceptar su servidumbre, ya que éste nos recuerda constantemente su decadencia progresiva y la finitud. Pero también hay que reconocer su dominio. Hay muchas frases de Nietzsche referidas a la hegemonía del cuerpo, hasta el punto en que afirma que no somos nada más que cuerpo y el alma no es más que una palabra para hablar de él. El filósofo alemán nos avisa también de que el yo y las otras formas de designarlo son un espejismo que oscurece el reinado 
de ese monarca ante quien abdicamos sin saberlo. Cuando olvidamos su soberanía nos convertimos en espectadores impotentes del soma, aún siendo éste parte indivisible del yo. En esos momentos el cuerpo aparece como algo pesado y extraño. Ése es el destino de los despreciadores del cuerpo, muy parecido al de un Sísifo condenado a arrastrar ladera arriba la pesada piedra en que se ha convertido su cuerpo.

\section{LA SOMBRA DEL CIPRÉS ES ALARGADA}

La anoréxica insiste en que su sombra sea cada vez más estrecha y alargada hasta que acaba pareciéndose peligrosamente a la de un ciprés. A medida que el trastorno avanza, la piel, cada día más traslúcida, se va transformando en un rígido lienzo que la amortaja.

Recalcati, dentro del psicoanálisis, concibe la anorexia como una maniobra para salvaguardar el deseo. El sujeto se decanta por la inanición física para protegerse de la inanición psíquica. En otras palabras, es como reclamar el derecho a respirar ahogándose. La anoréxica se sirve de este ardid de jugar a hacerse la muerta para garantizar así su supervivencia psíquica, pero llega un día en que la mismísima muerte aparece reflejada en el espejo y, al parecer, no la reconocen ni cuando la tienen delante de sus narices.

Una forma en que se pone de manifiesto la pulsión de muerte es aquella en que la pulsión de control, paradójicamente, acaba perdiendo el control sobre sí misma. También se manifiesta mediante el principio de Nirvana, término introducido por Schopenhauer para referirse a la tendencia del aparato psíquico a reducir a cero la tensión interna. En la anorexia asistimos, según Recalcati, a una radical nirvanización del sujeto, a su cadaverización progresiva, a su momificación. Ante el espejo, la anoréxica presencia de forma impasible su propia solidificación. Su vacío se encarna ante su orgullosa mirada. Su carne queda reducida a desierto, no solo se desexualiza, sino que también se desvitaliza convirtiéndose en materia pura. Irónicamente, el hecho de estar inmersa en esa especie de rigor mortis consigue acallar el sufrimiento previo al inicio del trastorno: el propio del duelo por aquella niña que su figura la impedía ser.

Hoy día, la muerte es excluida del discurso dominante. Nuestra cultura trata por todos los medios de borrar las huellas del paso del tiempo y del deterioro de los cuerpos. Todo lo que es excluido del discurso dominante busca otra forma de retornar y salir a la luz; en este caso, encuentra en el cuerpo anoréxico un portavoz.

\section{UNA EPIDEMIA IN CRESCENDO}

«La anorexia es una mofa grotesca de los ideales de belleza que acaban mofándose de ti, es una rabieta visual» (Marya Hornbacher, Días perdidos) 
Graciela Strada señala que los síntomas tienen siempre una dimensión social. Los pacientes utilizan los valores predominantes de la cultura para encarnarlos y rebelarse contra ella. Foucault, afirma también que la existencia de una enfermedad mental en un tipo determinado de sociedad sirve como crítica de esa misma sociedad.

El mensaje transmitido por el cuerpo emaciado es contradictorio. Liz Eckerman (1) expone que actúa como una parodia de la sociedad disciplinaria que modela sujetos y cuerpos dóciles, actuando como su servidor más cumplidor; pero, al mismo tiempo, se resisten a los dictados de dicha sociedad al desafiar la autoridad de padres y profesionales de la salud en su búsqueda de una identidad independiente. La inanición voluntaria podría representar una solución personal a un problema social más amplio de carencia de orden y control por parte del individuo.

Desde este punto de vista, la sociedad que se pone en entredicho se caracteriza por la sensación de hambre y de falta que padecen sus habitantes a pesar de la opulencia que les rodea. El hombre moderno está hambriento de vida, dice Fromm (6). Se ha convertido en un autómata que hace los movimientos adecuados para vivir, pero como no puede experimentar la vida acepta cualquier sucedáneo. Los objetos de consumo ofrecen la ilusión de anular la falta del sujeto. Esta falta subjetiva taponada por el objeto de consumo se transforma en pseudofaltas, manteniendo de esa manera la ilusión de que la falta constitutiva del ser humano puede resolverse mágicamente y que el vacío que llevamos en lo más hondo de nuestro ser puede ser rellenado constantemente. Dentro de este discurso capitalista, el cuerpo se expone, se vende y consume como otra mercancía más.

Esta primacía de los objetos es tal que han sido muchos los que han anunciado el fin del sujeto. Así Foucault (25) escribe sobre la reciente invención del hombre y sobre su posible próximo fin. El precio que paga una sociedad que se rige fundamentalmente por la ética de la cantidad es la decadencia de la subjetividad.

Algunos sociólogos (26) denominan a esta cultura la «cultura del narcisismo» ya que está formada por individuos que viven únicamente para sí mismos, se niegan a hacerse adultos y son incapaces de aceptar la vejez. En una sociedad que teme no tener futuro, la gente considera como prioritario su derecho a la realización personal. La identidad de cada individuo se sostiene en el logro, y sobre todo en el coleccionismo de objetos convertidos en fetiches. Las personas se limitan a cumplir con la rutina, olvidan lo que significa realmente estar vivo y opacan su existencia con apariencias.

En el ámbito del psicoanálisis, Heinz Kohut piensa que el mito de Narciso es el más adecuado para representar a una humanidad fascinada por su imagen. Este mito encarna a la perfección a un individuo reducido a contemplarse en la desdicha infinita de su imagen: el hombre trágico del psicoanálisis del self.

En esta «cultura del narcisismo» la obsesión dominante es vivir el presente. En este mundo impera lo efímero y se rinde culto al instante, se sacraliza el presente de tal manera que el tiempo está mutilado. En palabras de Sartre, lo han privado de 
pasado y de porvenir para reducirlo a la intuición pura del instante. Hoy día se vive cada momento como si tuviera la trascendencia del instante del que hablaba Kierkegaard: fugaz y eterno a la vez. Se trata de una forma de vivir desesperada, parecida a la de un enfermo en fase terminal, ya que el instante se extingue al momento que surge, su nacimiento es su propio aniquilamiento.

La atención del individuo contemporáneo se centra en ciertas imágenes que a los pocos segundos se olvidan. No existe fidelidad a nada que se extienda en el tiempo. La televisión, principal proveedora de modelos de identificación hoy en día, crea mitos constantemente. Esos mitos hacen que sintamos lo contingente como eterno. En un contexto muy diferente del que esas palabras fueron pronunciadas por Nietzsche, se puede decir que «el mundo verdadero se ha convertido en una fábula». Asistimos a la desrealización de nuestro mundo, al debilitamiento de la realidad de cada uno ya que resulta casi imposible distinguir nuestro mundo del construido para nosotros por los medios de comunicación. Estamos atrapados en el fraude de esa ficción sin que haya posibilidad de salvarse escapando a un universo construido únicamente por nosotros mismos. De hecho, utiliza unos mecanismos tan efectivos que ni siquiera nos planteamos la posibilidad de que haya otros mundos a donde poder huir.

Erich Fromm (6) escribió sobre la creciente estandarización de los individuos y de la ilusión de individualidad. Hoy lo normal es estar delgado, el sobrepeso y la obesidad no se consideran una enfermedad sino una especie de blasfemia por la que la persona que lo padece tiene que suplicar perdón ante las miradas acusadoras de quienes le rodean. Fromm resaltó la seguridad que da el ajustarse a la normalidad, pero a menudo olvidamos que nada está más cerca de la patología que el culto de la normalidad llevado al extremo (12).

\section{EVOLUCIÓN HISTÓRICA DE LOS TRASTORNOS DE ALIMENTACIÓN}

Se han producido algunos cambios a lo largo de la historia de los trastornos de alimentación. Antes, las anoréxicas solían tener rasgos de personalidad dependiente 0 rasgos obsesivos, hecho relacionado con la importancia que tenía para la mujer cumplir con su deber en la sociedad patriarcal. Hoy predomina la sintomatología bulímica y las pacientes suelen tener rasgos de personalidad borderline o narcisista.

Así por ejemplo Marta presentaba rasgos de personalidad borderline: déficit de autoestima, inestabilidad emocional, sentimientos de vacío, tendencia a la autodestrucción y al autodesprecio. Parecía poseída por la necesidad de destruir su belleza. En su caso el control alimentario respondía a un intento de estabilizar su fluctuante y caótico mundo interno. Hacía ejercicio físico en extremo. La hiperactividad y la búsqueda de excitación y «sensaciones fuertes» tenían en ella una finalidad fundamentalmente antidepresiva, como una defensa maníaca. Cuando empecé a verla se 
daba atracones, abusaba del alcohol y tomaba laxantes sin control. Mediante estos mecanismos lograba sentir una debilidad extrema, una sensación de paz que ponía un efímero fin a su inconmensurable angustia.

La anorexia no es un capricho, expresa un sufrimiento a la vez que es una defensa frente a él. Como expondré a continuación, en el tratamiento de Marta para lograr algún avance fue esencial el llegar a un acuerdo con ella acerca de la función que la anorexia había cumplido en su vida.

\section{UN ACTO DE VALENTÍA}

Sacar la cabeza de ese altar donde la anoréxica se sacrifica, el retrete, y volver a comer de una forma saludable es un acto de valentía. A lo largo del tratamiento tratamos de contestar a una serie de preguntas.

1. ¿Qué malestar de fondo se cura mediante la anorexia?

2. ¿Qué hace a una persona despreciar los esfuerzos de supervivencia de su cuerpo, tratar de destruirlo y corroerlo con vómitos y laxantes?

3. ¿Qué rol ha desempeñado -y desempeña- la anorexia en su vida?

4. ¿Qué es ella si deja de ser anoréxica? ¿Qué lugar ocupará para los demás?

Para avanzar en el tratamiento fue esencial llegar a un acuerdo con la paciente sobre las razones que llevaron a la elección de la anorexia como intento desesperado de exorcizar su sufrimiento, o lo que es lo mismo contestar a la pregunta qué malestar de fondo se cura mediante la anorexia. La preocupación por el peso es una cortina de humo que suele esconder un sufrimiento subcutáneo aún mayor. En el caso de Marta el miedo a ser mediocre, a no cumplir con las altas expectativas que tenían sus padres sobre ella.

La respuesta a la segunda pregunta tiene que ver con su estructura de personalidad. En las patologías borderline son frecuentes las conductas autodestructivas en relación con los problemas de identidad y autoimagen. Los rasgos de personalidad son más complicados de modificar y se trata del aspecto que a día de hoy estamos todavía abordando.

Respecto al rol que ha desempeñado la anorexia en su vida, hay que tener en cuenta que todo síntoma sirve de refugio para la existencia psíquica del sujeto (9). Detrás del síntoma está el propio sujeto alojado en una representación sustitutiva más aceptable. La anorexia es un desafío a todo discurso que excluya un espacio para el sujeto, como ya he comentado, proporciona una identidad, una sutura, permite existir como sujeto. En el caso de Marta esta identidad de "ser anoréxica» la sirvió para no estudiar las asignaturas de una carrera que ella no había elegido; como excusa cuando algo la salía mal para no decepcionarse a sí misma; la proporcionó la atención de amigos, familiares y la permitió seguir siendo niña ya que sus padres no 
la exigían apenas responsabilidad porque estaba enferma. Otros autores han apuntado otras funciones que cumple la anorexia. Así Recalcatti (22) afirma que para evitar la muerte del deseo, la anoréxica se afirma sobre un deseo de muerte.

Por otra parte, la anorexia es una especie de pulso con los padres. A través de ella conquista una posición de supremacía o dominio imaginario respecto a ellos. Se trata de una maniobra de separación necesaria para adquirir el estatuto de sujeto (22).

Hasta entonces, por irónico que pueda parecer, Marta había luchado por tener un lugar en el mundo ocupando cada vez menos espacio. A lo largo del tratamiento aprendió a valorarse no como una buena anoréxica, sino como una buena amiga, compañera, novia y, finalmente, hija. Aprendió a tomar decisiones autónomas, así por ejemplo cambió de carrera durante el tratamiento. En definitiva, se fomentó una identidad no tan frágil como aquella sostenida únicamente en una imagen que desaparece en cuanto cierras los ojos.

\section{MÁS ACÁ DEL ESPEJO}

En la segunda parte de «Alicia en el país de las maravillas» el personaje de Carroll atraviesa el espejo para ir a parar al mundo al revés de los adultos. Marta no quería atravesar ese umbral, pero su cuerpo tampoco la permitía quedarse más acá del espejo.

El primer Foucault (27) destaca la importancia de la imagen y de la imaginación para entender las enfermedades mentales. Imaginar implica trascender, ir más allá de la presencia de cualquier imagen. La imagen, justo lo contrario de imaginar, es siempre una parálisis.

Estas pacientes parecen quedar apresadas dentro del marco estático y fijo del espejo, atascadas en una imagen que no las deja ir más allá. Esa imagen se convierte en un icono al que adorar. Al principio las proporciona un estado de dicha, podría decirse que posan fundamentalmente para ellas mismas: «Cada mirada furtiva al espejo lleva en sí como un relámpago de vicio secreto» (28).

Para lograr mantener este efecto aprenden a ver las cosas como si estuvieran reflejadas en espejos cóncavos. Bruch (5)dice que las anoréxicas aprenden a engañarse a la hora de percibir el tamaño de su cuerpo, aprenden a percibir también como más grande la figura de los demás e incluso tienden a aumentar la longitud de distancias abstractas.

Poco a poco, la anorexia se convierte en una oda a la insatisfacción. El espejo siempre le devuelve una imagen imperfecta. De repente, la anoréxica se ve reflejada en las pupilas de alguien cada día más exigente. La anoréxica, al igual que el resto de los mortales, se encuentra persiguiendo un espejismo, sólo que el suyo está localizado en esa imagen ideal convertida en fetiche. 
La frase de Ortega y Gasset «Nuestro cuerpo desnuda nuestra alma, la anuncia y la va gritando por el mundo. Nuestra carne es un medio transparente donde da sus refracciones la intimidad que la habita» hace referencia a un espejismo ya que éstos son un producto de la refracción. La quimera que buscamos sin cesar habita dentro de nosotros, bajo las capas de carne y tejido que la anoréxica se obceca en anular. La naturaleza dividida del ser humano de la que hablan los lacanianos hace que seamos en gran medida unos perfectos desconocidos. De esta manera, no solo nos encontramos con que hay veces en que hay otro, que no soy del todo yo, que utiliza mis cuerdas vocales para expresarse sino que también ese otro, que no coincide del todo conmigo mismo, utiliza mis ojos para ver a través de ellos. No acabamos de reconocer a ese juez cruel que nos juzga desde dentro, ni tampoco a ese extraño que nos hace aspirar a la perfección y configura la utopía que anhelamos alcanzar.

El cuerpo anoréxico contiene un mensaje dirigido a un destinatario (9). Los principales destinatarios suelen ser los padres, el mensaje algo que hay que descifrar junto a la paciente. Una paciente decía que la anorexia es un intento de sacar el dolor que llevas dentro, de hacerlo pasar del alma a la piel. La piel se convierte así en la portavoz de un cuerpo que chilla pidiendo la ayuda que las cuerdas vocales no aciertan a pronunciar.

En este caso quedaría muy apropiado decir que Marta y sus padres vivieron felices y comieron perdices, pero eso no sería del todo cierto. Aunque logró alcanzar un peso saludable y llevar una alimentación sana, sin vómitos ni atracones, a día de hoy sigue pendiente del peso y de la comida.

El cuerpo ni perdona ni olvida. Se ha dicho que las personas tendemos a grabar nuestro dolor sobre la misma hendidura. Probablemente, cada vez que aumente su nivel de angustia o sus sentimientos de vacío, Marta volverá a depositar su dolor en la misma herida. Volverá a mirarnos desde el espejo porque desde allí, a una distancia prudencial, suele sentirse más segura. Volverá a poner el mundo entre paréntesis cada vez que lo encuentre amenazante y es posible que sea así hasta que no aprenda a leer lo que sus heridas la susurran, lo que ella misma se cuenta a través de las llagas que se provoca. Cuando haya descifrado su mensaje, tendrá que aprender otras maneras de decirse a sí misma y a los demás las cosas. Solo entonces recuperará las ganas de seguir viviendo, ya que como dice Pedro Salinas «querer vivir es anhelar la carne, donde se vive y por la que se muere. Se busca obscuramente y sin saberlo un cuerpo». 


\section{BIBLIOGRAFÍA}

1. Eckerman, L., Foucault, embodiment and gendered subjectivities: The case of voluntary self-starvation en Foucault, Health and Medicine, London, Routledge, 1997.

2. Hornbacher, M., Días perdidos, Barcelona, Mondadori, 1999.

3. Guidano, V.; Liotti, G., Cognitive processes and emocional Disorders: a structural approach to psychotherapy, New York, Guilford Press, 1983.

4. Merleau-Ponty, M., Fenomenología de la percepción, Barcelona, Península, 1975.

5. Bruch, H. La jaula dorada: el enigma de la anorexia nerviosa, Barcelona, Paidós, 2001.

6. Fromm, E., El miedo a la libertad, Barcelona, Paidós, 2000.

7. Amorós, C., Kierkegaard o la subjetividad del caballero, Barcelona, Anthropos, 1987.

8. Dostoievski, F., Los hermanos Karamazov, Madrid, Cátedra, 1987.

9. Strada, G., El desafío de la anorexia, Madrid, Síntesis, 2002.

10. Foucault, M., Vigilar y castigar: nacimiento de la prisión, México, Siglo XXI, 1986.

11. Barthes, R., La cámara lúcida: Nota sobre la fotografía, Barcelona, Paidós, 1990.

12. Roudinesco, E., ¿Por qué el psicoanálisis?, Barcelona, Paidós, 2000.

13. Baudrillard, J., «El más hermoso objeto de consumo: el cuerpo», en La sociedad de consumo, Barcelona, Plaza\&Janés, 1974.

14. Milton, J., El paraíso perdido, Madrid, Cátedra, 2003.

15. Vattimo, G., El sujeto y la máscara, Barcelona, Península, 1989

16. Faulkner, W., El sonido y la furia, Barcelona, Orbis, 1982.

17. Watzlawick, P., Barelas, J.B., Jackson, D.D., Teoría de la comunicación humana: interacciones, patologías y paradojas. Barcelona, herder, 1995.

18. Selvini Palazzoli, M., Muchachas anoréxicas y bulímicas: la terapia familiar, Barcelona, Paidós, 1999.

19. Favazza, A.R.; Conterio, K., «Female habitual self-mutilators», Acta Psyquiatrica Scandinavia, 79, pp. 283-289.

20. Camus, A., El mito de Sísifo, Madrid, Alianza Editorial, 2000.

21. Nietzsche, F., La gaya ciencia, Madrid, Alba, 1996.

22. Recalcati, M., Clínica del vacío: anorexias, dependencias, psicosis, Madrid, Síntesis, 2003.

23. Blanchot, M., Aminadab, Nebraska, University of Nebraska Press, 2002.

24. Marcuse, H., «La ideología de la muerte» en Ensayos sobre política y cultura, Barcelona, Planeta, 1986. 
25. Foucault, M., Las palabras y las cosas: una arqueología de las ciencias humanas, Buenos Aires, Planeta, 1988.

26. Lasch, C., The culture of narcissism, New York, Warner Books, 1989.

27. Foucault, M., Dream and existente, New Jersey, Humanities Press, 1993.

28. Kundera, M., La insoportable levedad del ser, Barcelona, Tusquets, 1993.

Rebeca García Nieto

P.I.R. Psicólogo Interno Residente

Hospital Psquiátrico "Doctor Villacian". Valladolid

Dirección:

Rebeca García Nieto

C/ García Morato $29^{\circ}-2^{\circ} \mathrm{T}$

47007 VALLADOLID

E-mail: rebecag2001@yahoo.es

Tel.: 983-132368 • Móvil: 695182393 